The Use Of Translation Tool...., Rizka Mahardika, 49-56

\title{
THE USE OF TRANSLATION TOOL IN EFL LEARNING: DO MACHINE TRANSLATION GIVE POSITIVE IMPACT IN LANGUAGE LEARNING?
}

\author{
Rizka Mahardika \\ Universitas Negeri Malang \\ Email: rmahardika92@gmail.com
}

\begin{abstract}
Translation tools are commonly used for translating a text written in one language (source language) into another language (target language). They are used to help translators in translating big numbers of translation works in effective time. There are three types of translation tools being studied in the article entitled Machine Translation Tools: Tools of the Translator's Trade written by Peter Katsberg published in 2012. They are Fully Automated Machine Translation (or FAMT), Human Aided Machine Translation (or HAMT) and Machine Aided Human Translation (or MAHT). Katsberg analyzed how each translation tool works, the naturality and approriateness of its translation and the compatibility of using it. In this digital era, translation tools are not only popular among translators but also among EFL learners. Beginning with the use of portable dictionary such as Alfalink and expanding to the more sopisticated translation tool such as Google Translate. Some novice learners usually use this translation tools in doing their task without recorrecting the translation result. This happens perhaps because they do not have enough background knowledge to evaluate the translation result. Thus, it will be better when the learners have good mastery in basic English and train them to be aware in evaluating the result from translation tools. On the other words, Human Aided Machine Translation may be the wise choice to do translation task effectively and efficiently particularly in managing the time.
\end{abstract}

Keywords: Machine translation, Translator, Language learning.

\section{INTRODUCTION}

Translation tool is a software providing a system in which the system can predict the translation words from one language to another language. It is aimed at helping people in translating one language (source language) into another language (target language). However, translation tools have at least several limitation. Firstly, translation tools can only translate a language in the form of written text.
They cannot recognize language which uses orally or in the form of speech. The other limitation is that translation tools somehow cannot translate language in natural flow. They are lack of natural language processing.

According to Kastberg (2012), there are three types of translation tools which can be classified. They are Fully Automated Machine Translation (FAMT), Human Aided Machine Translation 
(HAMT) and Machine Aided Human Translation (MAHT). He divided those translation tools based on their degree of automation. Automation regards to who is the 'head' in the process of translation whether it is the software or the translator himself.

Kastberg described those three types of translation tool comprehensively in his article. He started by explaining the definition of each translation tool, its ability and how it processed the translation. He also elaborated the strengths and the weaknesses of each tool in order to give clear information to the reader as well as the translator who needs help from translation tools due to the great amount of text that he/she should translate.

However, he did not provide any information about the use of translation tools among language learners. Thus, this paper will try to expose some research in which the results are related to the translation tool and its effect to language learners and how far the translation tool influences language learner's performance. Since there is an assumption that there is a good effect regarding the use of machine translation in language learning. Before this paper develops a framework about the effect of using translation tools for language learner, the further explanation about translation tools from Kastberg will be elaborated as follows.

\section{Fully Automated Machine Translation (FAMT) \\ Fully Automated Machine} Translation (FAMT or simply called Machine Translation or MT) is a translation tool which has the full responsibility in translating the language. It works automatically after the translator input the source language. This tool is not interfered by the translator at all in its translation process.

Kastberg reviewed three types of FAMT. They are classified into:

Table 1. Types of Fully Automated Machine Translation

\begin{tabular}{|c|c|c|}
\hline No & Types of FAMT & Details \\
\hline 1 & $\begin{array}{l}\text { Direct MT- } \\
\text { Model }\end{array}$ & $\begin{array}{l}\text { - } \quad \text { Translating only based on } \\
\text { morphological analysis } \\
\text { Translating and analyzing single } \\
\text { word by word } \\
\text { Not able to translate words in } \\
\text { context } \\
\text { E.g. } \\
\text { German: [ich bin es] } \\
\text { English: [I am it] } \\
\text { It should be it is me. }\end{array}$ \\
\hline 2 & Transfer Model & $\begin{array}{l}\text { Translating based on } \\
\text { morphological, regional and } \\
\text { grammatical analysis or more } \\
\text { comprehensive analysis. } \\
\text { Translating and analyzing not only } \\
\text { single word by word but also } \\
\text { groups or strings of words that } \\
\text { attach together } \\
\text { Enable to translate word in context } \\
\text { with its individual morphological } \\
\text { description and its grammatical } \\
\text { description both in source language } \\
\text { and target language pattern } \\
\text { respectively then put them together } \\
\text { correctly. } \\
\text { E.g. } \\
\text { English: [the artificial flower] } \\
\text { French: } \\
\text { Direct MT-model [la artificielle } \\
\text { fleur] } \\
\text { Transfer model [la fleur artificielle] }\end{array}$ \\
\hline 3 & $\begin{array}{l}\text { Interlingua } \\
\text { Model }\end{array}$ & $\begin{array}{l}\text { Translating source language } \\
\text { globally and semantically correct to } \\
\text { the target language } \\
\text { Translating the source language to a } \\
\text { natural target language } \\
\text { Enable to analyze the actual } \\
\text { meaning or content of source } \\
\text { language in the process of } \\
\text { translating it into target language }\end{array}$ \\
\hline
\end{tabular}

Human Aided Machine Translation (HAMT)

HAMT is a software-such as SYSTRAN — which takes human as a consultant or an editor who can modify and suggest the translation result from the machine when he/she thinks that there are some words 
which is not suitable to the diction or word choice he/she wants. The human translator in HAMT-program may give his/her suggestion before, during, after or combination of those three phases.

If the human translator edits the source language before the machine processes the translation, it is called pre-editing. He/she makes adaptation the sequence words or sentences of the source language to make it similar to the target language's sequence. It is done to avoid the problem caused by the order of word which may happen to the target language like what emerged in the Direct MT-model.

If the human translator edits the source language during the machine processes the translation, it is called interactive editing. Naturally, the machine will query some questions to human translator which the answer is not provided in the machine input. For instance, the machine willl ask the human translator to choose the most appropriate words which is expected to be translated in the context of the source language. For example, the word "word" itself, in English, "word" has at least 7 meanings. "Word" can be word as a unit of language, word as something you say, word as a promise, word as information or news, word in a Bible, word as an exclamation of an agreement, or it may also mean technical terms as word in the context of "word break" and "word class". Thus, the machine needs to confirm which meaning is actually meant by the source text. This advantage cannot be found in the Direct-MT program since it analyze language locally as the consequence the program will choose the "primary meaning" which has been input by its programmer. In fact, the English vocabulary set is sometimes different from other language. In bahasa Indonesia, "word in a Bible" is called "firman", "word as information or news" is called "berita".

If the human translator edits the source language after the machine processes the translation, it is called post-editing. It will be like somewhat which is usually done by the teachers nowadays, who correct the student's assignment in translation class or the linguists and proofreaders who review texts made by other researchers.

In conclusion, by using an HAMT-program the translator is required to involved further in the translation process ultimately when he/she only does post-editing. The translator needs to compare the source text to the translation that has been processed by the HAMTprogram as he/she becomes the proofreader to check the acceptable words which has been translated.

\section{Machine Aided Human Translator (MAHT)}

MAHT is a software which is only used when the human translator needs to get some help from this program. The simplest production which can done by this software is checking the spelling and grammar used in the text. And the more sophisticated MAHT software are electronic dictionaries, terminology database, some other dictionary application which can be installed in PC or other gadgets. As Kastberg's paper states that the most 
sophisticated form of MAHTsoftware is Translation Memories (TM) including Computer Aided Translation (CAT).

However, Kastberg did not elaborate the MAHT-tools like spell check, grammar check and databases installed in Office solution since they are already developed for general PC not specifically for translator. $\mathrm{He}$ elaborated the software called Translation Memories which are already commonly used by the translators. Translator Memories is a smart software which can remember the words that have been used in its storage to be used when the same words appeared in the same context in a source text and translate them into the target language.

The translation process starts by typing the source text into the software. The act of inputting the source text is called alignment. The text which has been typed then exported to a text file and continuously imported to the actual translation memory. After this initial process has been accomplished, the translation process may begin. The translator will be displayed the source text and it has been splitted into Translation Units (TUs) — which are sentences. The translator will translate each TU and the software will record the original translation of the source text and its corresponding translation. In the process of translation, the software will store the "pairs" or the colloquial words into its database and the number will increase as the progress of the translation process. And every time the software recognizes a TU which has been translated preceeding, the translator will get a notification how he/she translated the similar TU before simultaneously. The work of translator will be easier, he/she only need to copy the previous translation to complete that TU. However, there is no $100 \%$ similarity in every $\mathrm{TU}$, the range is from $50 \%$ to $90 \%$ so that it will be up to the translator to modify which part needs editing. Furthermore, this software is also developed with search engine which enables the translator to search a word or translation unit stored in the database.

From the explanation above, Kastberg said that Translation Memory can be used to translated a huge number of pages which should be translated by the translator. It has an ability to recognize the same technical term with high degree of consistency in putting the most appropriate pair words in the same context of translation. However, the translator creativity can also be raised by using this software as the consequence of the repetition done by the software which may appear in the translation process.

\section{Machine Translation and Language Learners}

Language learners in this digital era are not similar with language learners who learn language in the era before technology has been invented and promoted to every part of this life. Based on Kastberg, first research related to machine translation was studied in the 1930s and the first machine translation developed in the 1940s and succeeded in the middle of 1950s achieved by some scientist from Georgetown University, USA. Grammar Translation Method had 
been a powerful method to teach language for centuries before communicative approach introduced to be the better method in teaching language. However, until now translation still has its popularity because by knowing how to transfer a language into another language the information will spread out around the world without boundaries. And that is one of the reasons thatlinguists have been trying to develop machine translation to help them in translating text.

Translators need the help from this machine particularly in translating big amount of text and so does the language learner. Language learner who is not proficient especially in English can use machine translation as the supporting tools which can help him/her in understanding English in his/her native language or vice versa. Gracia (2010) in his article states that:

"For language learning, the machine generated translation could offer a type of scaffolding upon which the individual student can project their grammatical knowledge on the other language. The teacher could find in it also a common platform for a class activity."

The result also proves that machine translation can help the beginner and early intermediate students to beef up their communication skill particularly in doing written task.

In another previous research related to this topic, Karnal and Vera (2013) found out thatthe use of Google Translate as the machine translation helped the non-proficient students comprehend some English source texts which have been translated into Portuguese by Google Translate. The result shows that the students could comprehend the texts $62 \%$ from the whole texts which had been given by the teacher after they were processed in Google Translate. It confirms that Google Translate may be used to support the students in comprehending the English texts although they are not proficient. Moreover, since machine translation is not able to naturally process translation as human being is, there were some grammatical errors emerged and it created chances for the teacher to build the student's awareness in finding linguistic error that might appeared in the translation.

In line with Karnal and Vera (2013), Korošec (2011) who previously conducted a research about applicability and challenges of using machine translation in translation training found out that the students only took the result from Google Translate to provide the first draft before they post-edits it. The students of translation training tend to be active in rechecking the translation from Google Translate rather than simply taking it for granted and submit their task to the translation teacher. They have been aware that Google Translate or any machine translation may have misinterpretation in translating some words from source language which have several meaning in the target language.

More detailed explanation is given by Kliffer (2005). He examined a machine translation named Power Translation Pro (PTP) and compared its result translation to student's work who were in their first year of French major in translating a French text 
into English. He found out that the error made by that program was more than what made by the students. The errors made by PTP appeared in the non-morphological pattern, it tended to misinterperate the discontinuous syntactical dependencies like mood choice of an embedded verb, which was determined by the main clause verb, and word choice related to semantical sense of meaning. The categories which mostly made errors in translating them are verbpreposition, tense, word order and word choices. Among 17 categories of errors, the program and the students only shared word choice and literal as double-digits percentage. After comparing the errors made by the program and the students, he then gave post-editing exercise and asked the students to post-edit the PTP translation of Montagnier interview. He also gathered the students' perspective about the usefulness of this exercise. The result shows that the lower proficient students appreciate more than the higher ones and it is also proven that the students felt less stressful in doing translation task when they had help from the PTP program to translate the text first and edited it later rather than translating the whole text by themselves.

In 2013, Cli ord, Merschel, Munné and Reisinger conducted a study toward the use of machine translation in language learning. They found out that there are some advantages that the participants gain by using machine translation. It can help them increase their vocabulary mastery, increase their grammatical accuracy, save their time, build selfconfidence, improve their grades and produce more native-like language. Most of them used this tool as dictionary. They used it either while they were writing the translation or editing and revising the text which had been translated first by the machine translation. Machine translation is not only used by the language learner in completing writing task but also helping them to comprehend text in reading class. It gives some directions while they are reading. In preparing oral assessment, this tool may provide the students some examples of right pronunciation and uncommon-needed vocabulary. However, besides those benefits, Cli ord, Merschel, Munné and Reisinger found that language learners, regarding their personal language knowledge, were aware of the mismatch and error made by the machine translations they had used. Positively, they considers them as an exercise in sharpening their error recognision to improve their proficiency. Contradictory, the language teachers have quite different perspective in seeing the usefulness of using machine translation used by students in language learning process. Most of them disagreed of using machine translation particularly for the students who were in their elementary level. The extreme opinion against the use of machine translation is that some language teachers thought that translation tool can expose incorrect input for their students because of the imperfection of its capability in translating text. Moreover, they also believed that 
the students rarely processed the output of this tool and made judgement whether it is right or wrong when they were given some tasks which made them possible to use machine translation.

\section{CONCLUSION}

This paper has given brief summary from Katsberg (2012) who described three types of translation tools named Fully Automated Machine Translation (FAMT or simply called Machine Translation or MT), Human Aided Machine Translation (HAMT) and Machine Aided Human Translation (MAHT). He explained the characteristics of each tool and how those tool work. Though he did not give any further information about their effects towards language learning. He only elaborated the use of machine translation among translators. Scientifically, machine translation can help humans save their time in translating texts since machine needs less time recalling the database that has been stored in its storage and directly processes the input of source language to become the output of target language. Thus, this paper tries to provide some research which has conducted by some researchers who are interested in studying machine translation as well as their influence in language learning. Although, there are some controversies regarding this topic particularly between student's and teacher's perpective in seeing the usefulness of machine translations, most of researchers agree that machine translations contribute positive impact toward language learning, especially for the students.
Through research, it is known that the language learners can learn foreign language by using machine translation. It could offer a type of scaffolding upon which the individual student can project their grammatical knowledge on the other language. For beginner and early immediate learners, they can improve their communication skill especially in written task (Garcia, 2010). Not only writting skill increases but machine translation can accomodate the the nonproficient students to comprehend reading text. With limited vocabulary mastery, they are still able to grasp the main idea of a text which is translated by machine translation though the comprehension percentage is only around 62\% (Karnal and Vera, 2013). In addition, from the affective aspect it is proven that machine translation brings positive impact to the students attitude towards learning. Kliffer (2005) found out that the students feel more comfortable and less stressful when they are doing translation task with the help of machine translation particularly for the students with lower proficiency. It is in line with the current research conducted by Cli ord, Merschel, Munné and Reisinger which ascertains that there are some advantages in using machine translation gathering from student's perspective. It help the students increase their vocabulary, increase their grammatical accuracy, save their time, build their confidence, improve their grades and produce more native-like language in their works. Though, not all teachers have the positive 
perspectives. Therefore, this paper is expected to give brief insight for the future research to ensure this good influence of using machine translation.

\section{REFERENCES}

Clifford, J., Merschel, L., Munné, J., and Reisinger, D. 2013. The Elephant in the Room: Machine Translation in the Language Classroom. Duke CIT Center for International Technology. Available at http://cit.duke.edu/wpcontent/uploads/2013/04/Elep hant-in-the-Room1.pdf. Accessed on March 27, 2014.

Garcia, I. 2010. Can Machine Translation Help the Language Learner?. International Conference: "ICT for Language Learning" $3^{\text {rd }}$ Edition. Available at http://conference. pixelonline.net/ICT4LL2010/c ommon/download/Proceeding s_pdf/TRAD02-Garcia.pdf. Accessed on March 27, 2014.

Karnal, A. R. and Vera, P. W. 2013. Reading Comprehension and the Use of Google Translator. International Journal of English Linguistics; Vol. 3, No. 6; 2013. Available at http://www.ccsenet.org/journa 1/index.php/ijel/article/view/29 280. Accessed on March 27, 2014.

Kastberg, P. 2012. Machine Translation Tools-Tools of the Translator's Trade. Communication \& Language at Work, issue no. 1, summer.
Available at http://ojs.statsbiblioteket.dk/in dex.php/claw/article/view/723 8. Accessed on March 27, 2014.

Kliffer, M. D. 2005. An Experiment in MT Post-Editing by a Class of Intermediate/Advanced French Majors ${ }^{1}$. EAMT 2005 Conference Proceedings. Available at http://www. researchgate.net/publication/2 39532270_An Experiment in MT Post-Editing by a Class of IntermediateAdvanc ed French Majors.1.

Accessed on March 27, 2014.

Korošec, K. M. 2011. Applicability and Challenges of Using Machine Translation in Translator Training. English Language Overseas Perspectives and Enquiries (ELOPE) Vol. 8 autumn. Available at http://www.sdas.edus.si/Elope /PDF/ElopeVol82KoletnikKorosec.pdf. Accessed on March 27, 2014. 